\title{
Electric Field Gradients at the In Site in Au-In Compounds*
}

\author{
P. Wodniecki, A. Kulińska, B. Wodniecka, and A. Z. Hrynkiewicz \\ H. Niewodniczański Institute of Nuclear Physics, 31-342 Cracow, Radzikowskiego 152, Poland
}

Z. Naturforsch. 53a, 349-354 (1998); received October 31, 1997

\begin{abstract}
The quadrupole interaction in Au-In compounds of different stoichiometries was studied with the perturbed angular correlation technique. The electric field gradients at ${ }^{111} \mathrm{Cd}$ probes were measured and the temperature dependences of the quadrupole frequencies were determined. A new high temperature phase of AuIn above $630 \mathrm{~K}$ and a new metastable modification of $\mathrm{Au}_{7} \mathrm{In}_{3}$ were found.
\end{abstract}

Key words: Perturbed Angular Correlations; EFG; Intermetallic Compounds; Au-In System.

\section{Introduction}

Interface compound studies on the Au-In system $[1,2]$ have shown that $\mathrm{AuIn}_{2}$ is formed below and around room temperature. AuIn $\mathrm{I}_{2}$ exhibits a $\mathrm{CaF}_{2}$ structure of cubic symmetry leading to a vanishing electric field gradient (EFG) at the lattice sites. Application of the perturbed angular correlation (PAC) method to detect the other intermetallic compounds formed in the interface region at elevated temperatures requires the knowledge of the hyperfine interactions of PAC probes, present in the lattices of the bulk compounds. We report a PAC study of bulk $\mathrm{Au}_{x} \operatorname{In}_{(1-x)}$ samples with different stoichiometries. The quadrupole interaction of ${ }^{111} \operatorname{In}\left(\beta^{-}\right)^{111} \mathrm{Cd}$ probe was observed at different temperatures. The EFG at ${ }^{111} \mathrm{Cd}$ was measured, but the actual position of probe nuclei is determined by that of the parent ${ }^{111} \mathrm{In}$, chemically identical with one of the compound constituents.

\section{Experimental Details and Data Analysis}

A series of bulk $A u_{x} \operatorname{In}_{(1-x)}$ samples of different stoichiometry, doped with ${ }^{111} \mathrm{In}$, was prepared in a following way. A carrier free solution of ${ }^{111}$ In in $0.04 \mathrm{M} \mathrm{HCl}$ was dried-out on the Au foil, and then the proper amounts of high purity gold and indium were melted under argon atmosphere in a resistance furnace. An appropriate annealing in sealed and evacuated quartz tubes ensured the homogeneity of the samples.

\footnotetext{
* Presented at the XIVth International Symposium on Nu-
} clear Quadrupole Interactions, Pisa, Italy, July 20-25, 1997.

Reprint requests to Dr. P. Wodniecki, Fax: 0 48-12-6370222.
The PAC measurements were performed at different temperatures $(24 \mathrm{~K}-700 \mathrm{~K})$ using a standard four $\mathrm{BaF}_{2}$ detector setup. From these measurements the perturbation factors were obtained and fitted by the appropriate theoretical function describing the static quadrupole interaction [3]. The fitted quadrupole interaction parameters

$$
v_{Q}=e Q V_{z z} / h
$$

(which can be displayed by the Fourier transform of the measured perturbation function) and

$$
\eta=\left(V_{x x}-V_{y y}\right) / V_{z z}
$$

are directly related to the components $V_{i i}$ of the diagonalized EFG tensor and to the known electric quadrupole moment $Q$ of the $247 \mathrm{keV}$ state in the ${ }^{111} \mathrm{Cd}$ probe [4]. A broadening of the EFG is described by the width $\delta$ of the Lorentzian $v_{Q}$ distribution.

The temperature dependence of quadrupole frequencies measured in $\mathrm{Au}_{70} \mathrm{In}_{30}$ and $\mathrm{Au}_{75} \mathrm{In}_{25}$ samples was fitted with the equation:

$$
v_{Q}(T)=v_{Q}(0)[1-a T] .
$$

\section{Results}

\subsection{The AuIn Phase}

The AuIn compound is stable at room temperature and melts congruently at $783 \mathrm{~K}$. Its composition range is very narrow. This phase is reported to be triclinic [5] but its structure type is not defined.

The PAC spectra were taken at different temperatures between $300 \mathrm{~K}$ and $800 \mathrm{~K}$. At about $630 \mathrm{~K}$ a polymorphic phase transformation was found, result- 

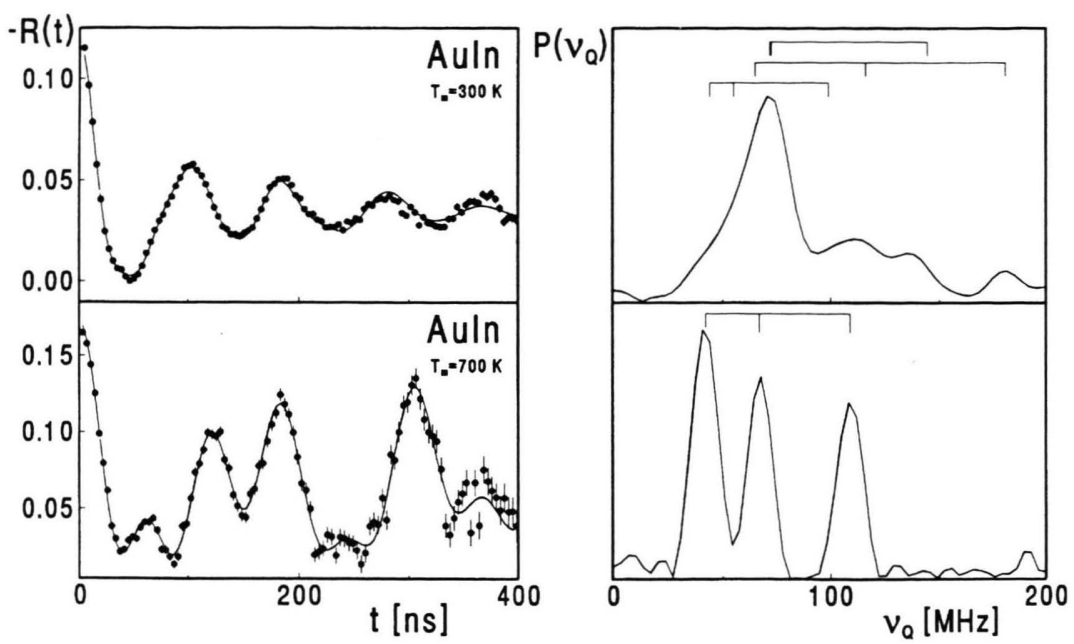

Fig. 1. PAC patterns (together with the corresponding Fourier transforms) measured at ${ }^{111} \mathrm{Cd}$ in an $\mathrm{Au}_{50} \mathrm{In}_{50}$ sample at different temperatures $T_{m}$. ing in a change of the PAC pattern (see Figure 1). Above this temperature one well defined quadrupole frequency of 34.7 (4) $\mathrm{MHz}$ with $\eta=0.47$ (1) was measured, nearly constant up to the melting point. Below $630 \mathrm{~K}$ three quadrupole frequencies were necessary to fit the PAC spectra (see Figure 1 and Table 1). This reproducible and reversible transformation, obtained for 4 samples of different stoichiometries close to the $1: 1$ composition is incompatible with the Au-In phase diagrams given in the literature, which report a single phase AuIn compound in the whole temperature range $300 \mathrm{~K}-783 \mathrm{~K}$ (Figure 2). Our result is also in disagreement with the $v_{Q}=63.4(10) \mathrm{MHz}$ and $\eta=0.3$ values reported for this phase in [6].

\subsection{The $\gamma$ and $\gamma^{\prime}$ Phase $\left(A u_{9} I_{4}\right.$ and $\left.A u_{7} I_{3}\right)$}

The high temperature $\gamma$ phase undergoes a transformation to the $\gamma^{\prime}$ phase having a different structure between $647.6 \mathrm{~K}$ and $637.5 \mathrm{~K}$. The approximate atomic composition of the $\gamma$ phase is $\mathrm{Au}_{9} \mathrm{In}_{4}$. Its equilibrium domain at low temperature is very narrow at approximately 30 at. $\%$ In, but at higher temperatures the phase region extends from 29.5 to 39.5 at. \% In [7]. It crystallizes in the $\mathrm{Cu}_{9} \mathrm{Al}_{4}$-type structure [8]. The low temperature $\gamma^{\prime}$ phase of $\mathrm{Au}_{7} \mathrm{In}_{3}$ stoichiometry has a hexagonal crystal structure with 60 atoms in the elementary cell $[8]$ and is observed in a very narrow composition range.

PAC measurements performed on the $\mathrm{Au}_{0.70} \mathrm{In}_{0.30}$ sample above $650 \mathrm{~K}$ resulted in two electric field gradients attributed to the 4(e) and 12 (i) indium sites in the $\mathrm{Au}_{9} \mathrm{In}_{4}$ phase of $\mathrm{D} 8_{3} \gamma$-brass structure (Figure 3 ).
Table 1. The quadrupole interaction parameters of ${ }^{111} \mathrm{Cd}$ in Au-In compounds: the quadrupole interaction frequency $v_{Q}$, the asymmetry parameter $\eta$ and the parameters $v_{Q}(0)$ and $a$ of the temperature dependence $v_{Q}(T)=v_{Q}(0)(1-a T)$.

\begin{tabular}{|c|c|c|c|c|c|c|}
\hline $\begin{array}{l}\text { Compound } \\
\text { phase }\end{array}$ & Structure & $\begin{array}{l}v_{Q}(300 \mathrm{~K}) \\
{[\mathrm{MHz}]}\end{array}$ & & $\begin{array}{l}v_{Q}(0) \\
{[\mathrm{MHz}]}\end{array}$ & $\begin{array}{l}a \\
{\left[10^{-4}\right.} \\
\left.\mathrm{K}^{-1}\right]\end{array}$ & $\begin{array}{l}\text { Lattice } \\
\text { site }\end{array}$ \\
\hline AuIn & triclinic & $\begin{array}{l}30(1) \\
41(1) \\
59(1)\end{array}$ & $\begin{array}{l}0.73(5) \\
1.00(2) \\
0.34(2)\end{array}$ & & & \\
\hline $\begin{array}{l}\text { AuIn } \\
\text { ht }\end{array}$ & $?$ & $34.7(4)^{*}$ & $0.47(1)$ & & & \\
\hline $\begin{array}{l}\mathrm{Au}_{7} \mathrm{In}_{3} \\
\gamma^{\prime}\end{array}$ & hexagonal & $\begin{array}{r}84(1) \\
101(1) \\
111(1)\end{array}$ & $\begin{array}{l}0.86(1) \\
0.95(1) \\
0.68(1)\end{array}$ & $\begin{array}{r}91(1) \\
107(1) \\
121(1)\end{array}$ & $\begin{array}{l}2.6(10) \\
2.06(4) \\
2.80(7)\end{array}$ & $\begin{array}{l}6(g) 1 \\
6(g) 1 \\
6(g) 1\end{array}$ \\
\hline $\begin{array}{l}\mathrm{Au}_{7} \mathrm{In}_{3} \\
\text { quenched } \\
\text { from } 700 \mathrm{~K}\end{array}$ & ? & $\begin{array}{r}86(1) \\
107(1) \\
116(1)\end{array}$ & $\begin{array}{l}0.63(1) \\
0.65(1) \\
0.42(1)\end{array}$ & $\begin{array}{r}92(2) \\
113(1) \\
120(1)\end{array}$ & $\begin{array}{ll}2.1 & (6) \\
1.7 & (4) \\
1.0 & (2)\end{array}$ & \\
\hline $\begin{array}{l}\mathrm{Au}_{9} \mathrm{In}_{4} \\
\text { ht } \gamma\end{array}$ & $\begin{array}{l}\text { cubic } \\
? D 8_{3}\end{array}$ & $\begin{array}{l}105(4)^{* *} \\
102(2)^{* *}\end{array}$ & $\begin{array}{l}0.00(1) \\
0.36(2)\end{array}$ & & & $\begin{array}{l}? 4(e) 3 \mathrm{~m} \\
? 12(i) \mathrm{m}\end{array}$ \\
\hline $\begin{array}{l}\mathrm{Au}_{3} \mathrm{In} \\
\varepsilon^{\prime}\end{array}$ & $\begin{array}{l}\text { orthorhom. } \\
\mathrm{DO}_{a}\end{array}$ & $26.2(3)$ & $0.19(1)$ & $28.6(3)$ & $3.2(2)$ & $2(a) \mathrm{mm} 2$ \\
\hline
\end{tabular}

* data from $700 \mathrm{~K},{ }^{* *}$ data from $T=655 \mathrm{~K}$.

The observed EFG distributions were large (see Figure 4), as for the other $\gamma$-brasses [9]. Below $650 \mathrm{~K}$ the $\mathrm{Au}_{7} \mathrm{In}_{3}$ phase was detected. According to its structure [8] three nonaxial EFG's with equal contributions were observed in the PAC patterns (see Table 1). The corresponding unique quadrupole frequencies exhibit a linear temperature dependence (Figure 4). The fitted slope parameters of (3) are listed in Table 1. 
Weight Percent Indium

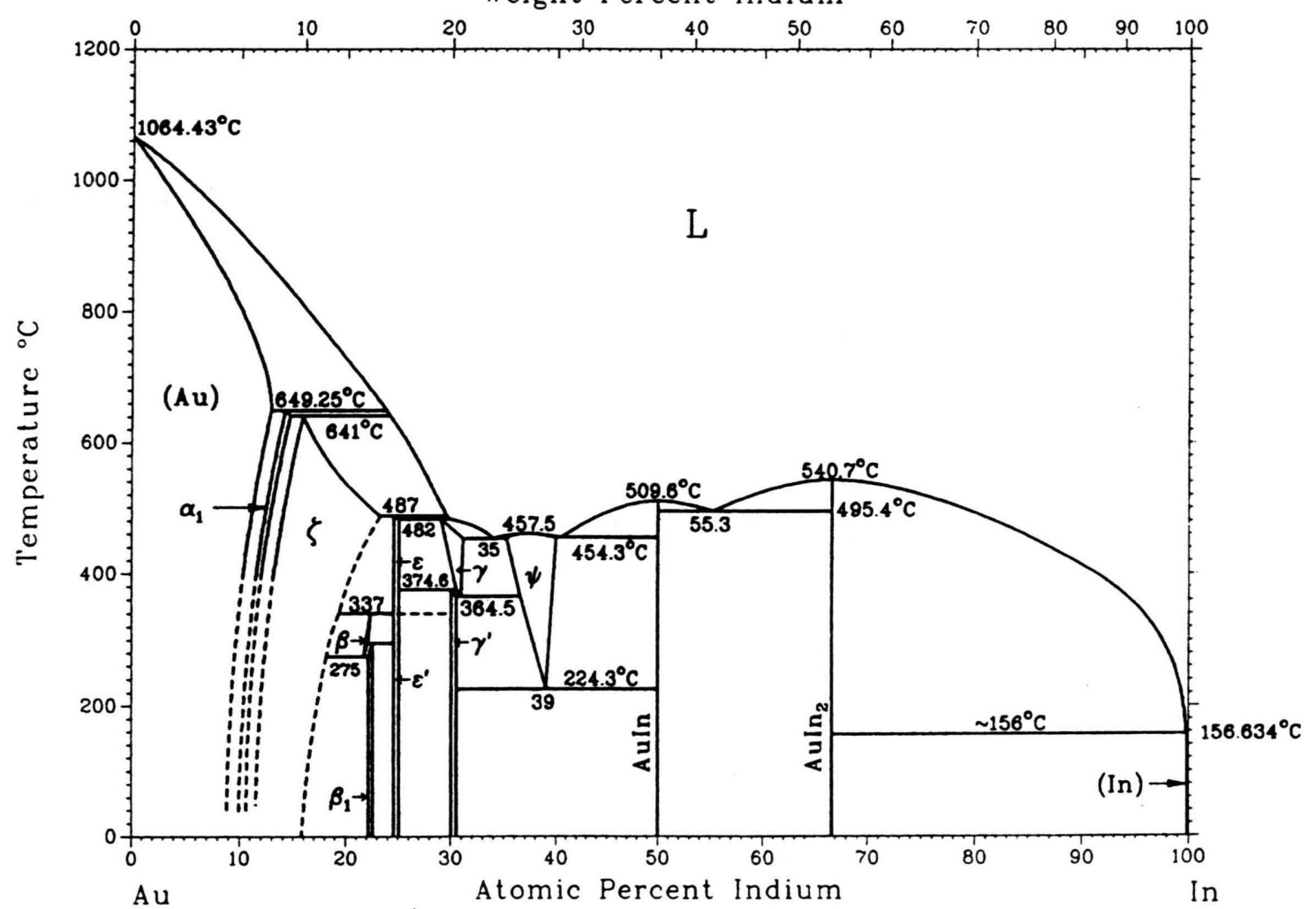

Fig. 2. Phase diagram of the Au-In system (after Okamoto et al. [13]).
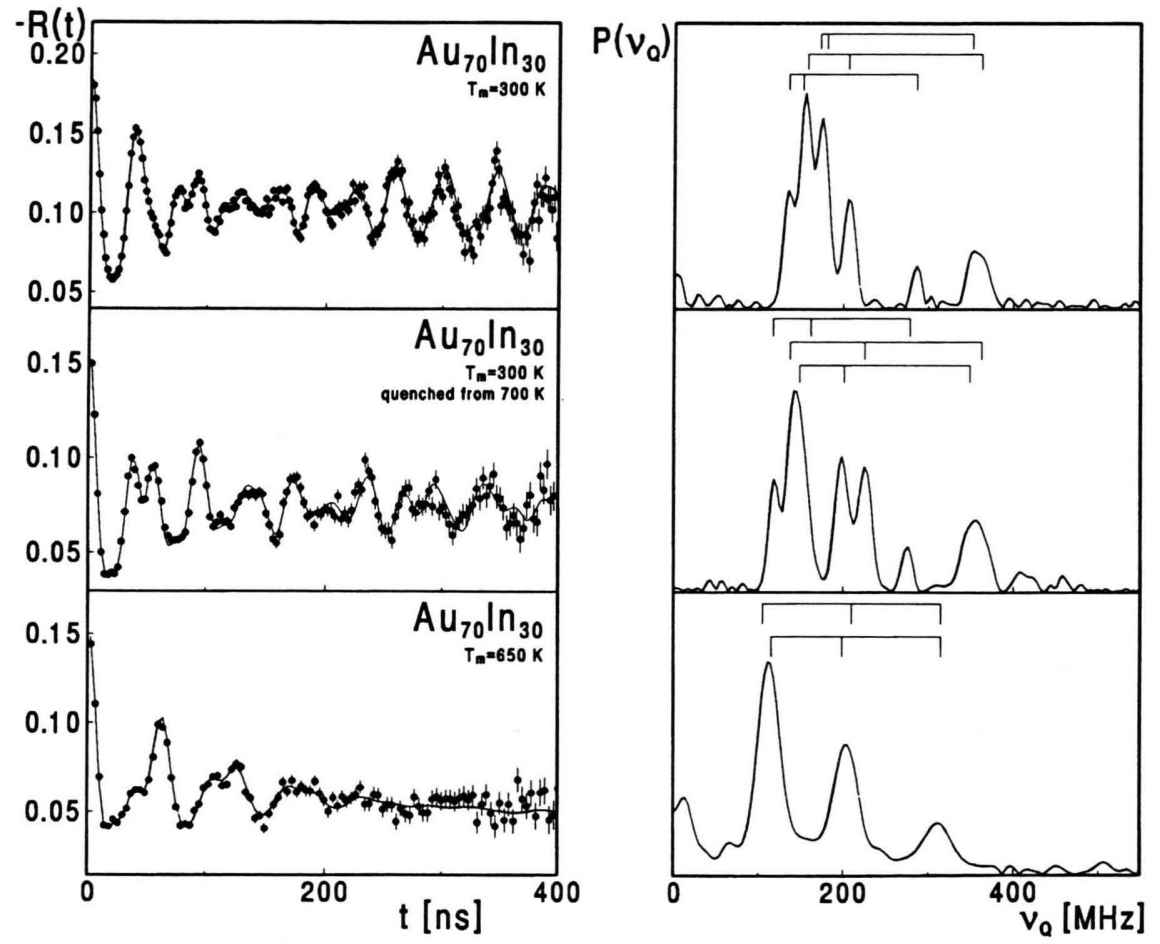

Fig. 3. PAC patterns (together with the corresponding Fourier transforms) measured at ${ }^{111} \mathrm{Cd}$ in an $\mathrm{Au}_{70} \mathrm{In}_{30}$ sample at different temperatures $T_{m}$. 


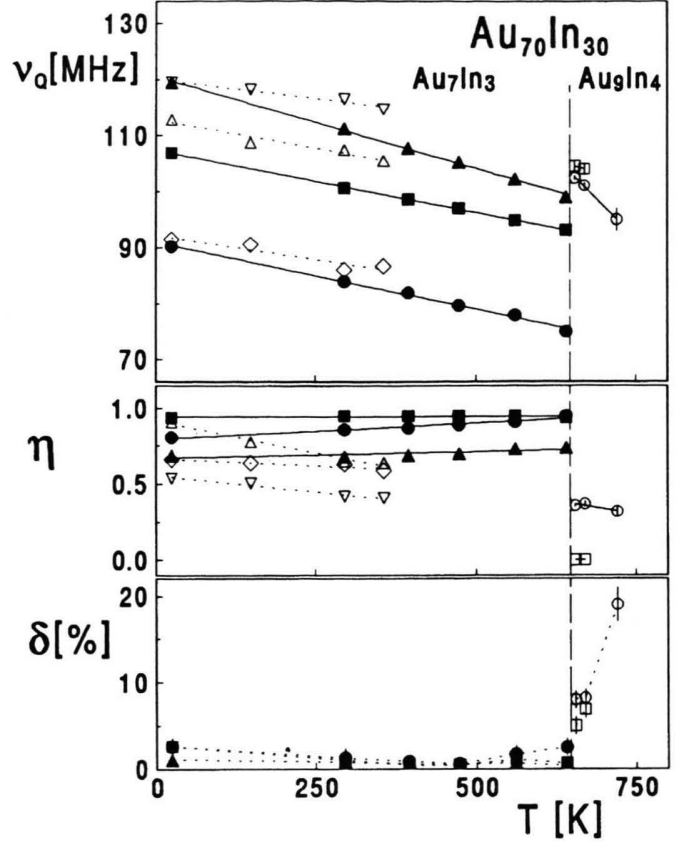

Fig. 4. Temperature dependence of quadrupole interaction parameters (quadrupole frequency $v_{q}$, asymmetry parameter $\eta$ and the width $\delta$ of the EFG Lorentzian distribution) in an $\mathrm{Au}_{70} \mathrm{In}_{30}$ sample. Empty symbols below $T=400 \mathrm{~K}$ correspond to the unknown phase obtained by quenching from $700 \mathrm{~K}$.

The same samples quenched in water from temperatures above $700 \mathrm{~K}(700 \mathrm{~K}, 730 \mathrm{~K}$ and $870 \mathrm{~K})$, i.e. above the $\gamma^{\prime}$ phase domain, exhibit three different EFGs. This result indicates the formation of a new, not previously known, phase. The corresponding PAC spectrum measured at room temperature is presented in Figure 3. Two In sites corresponding to the higher quadrupole frequency values $(107 \mathrm{MHz}$ and $116 \mathrm{MHz}$ - see Table 1 ) are equally (ca. $42 \%$ each) populated. The PAC spectra taken at different temperatures proved that this new phase is stable up to $350 \mathrm{~K}$ and undergoes a transformation to the $\gamma^{\prime}$ phase at $435 \mathrm{~K}$.
In order to check reproducibility of this result an additional set of PAC measurements for three samples with the atomic indium concentrations close to 30 at. $\%$ was executed. For all these specimens, quenched from ca. $870 \mathrm{~K}$, the same PAC pattern characteristic for the previously unreported phase was evidenced. This phase, observed as a $100 \%$ contribution in the samples of 30 at.\% indium concentration, was also evidenced for some other sample stoichiometries after quenching, but not as the single phase product.

It should be emphasized, that the same samples of 30 at. \% indium concentration, quenched from temperatures below the $\gamma-\gamma^{\prime}$ phase transition, do not exhibit this new structure but the PAC spectra typical for the $\gamma^{\prime}$ phase.

One should also mention the result of Goral and Eyring [10] obtained in a high resolution microscopy study of gold-indium bilayers. They report the existence of a superstructure form of the $\mathrm{Au}_{7} \mathrm{In}_{3} \gamma^{\prime}$ phase with a doubling of the hexagonal $a$ axis. It is an open question, whether the phase observed in our experiments is identical with the superstructure mentioned above.

\subsection{The $\varepsilon^{\prime}$ Phase $\left(A u_{3} I n\right)$}

The $\mathrm{Au}_{3} \mathrm{In}$ phase has a composition of $\approx 25 \mathrm{at} . \% \mathrm{In}$ and is isotypic with $\mathrm{Cu}_{3} \mathrm{Ti}$ [11]. Between 572 and $612 \mathrm{~K}$ it undergoes an order-disorder transformation $\left(\varepsilon^{\prime} \leftrightarrow \varepsilon\right)$ and decomposes peritectically at $765.5 \mathrm{~K}$ [7]. $\varepsilon^{\prime}$ and $\varepsilon$ represent ordered and disordered orthorhombic structures.

In $\mathrm{Au}_{75} \mathrm{In}_{25}$ one nonaxial electric field gradient was evidenced in the PAC pattern (Figure 5) and ascribed to the $\mathrm{Au}_{3}$ In compound of $\mathrm{DO}_{a}$ structure [12]. It's value also linearly decreases with the rise of temperature (Figure 6 and Table 1). An order-disorder phase transformation in $\mathrm{Au}_{3} \mathrm{In}$, manifested by the increase of the widths $\delta$ of quadrupole frequency distributions above $600 \mathrm{~K}$ (Figure 6), was observed in agreement with the phase diagram [13].

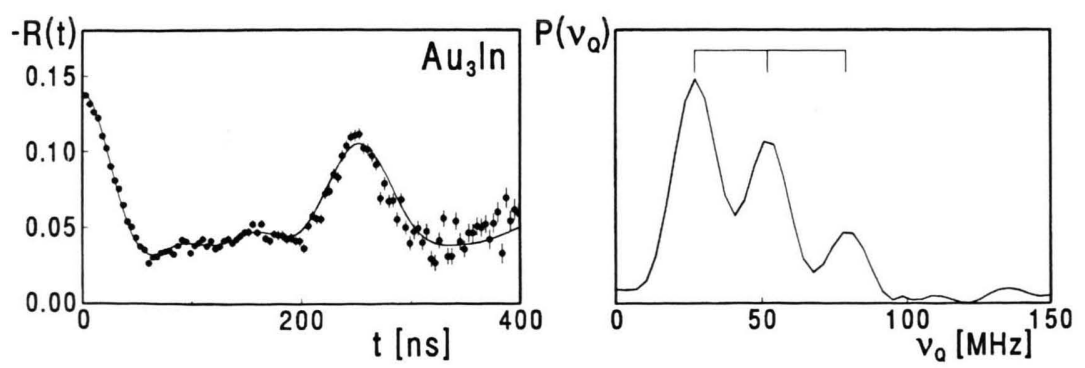

Fig. 5. Room temperature PAC spectrum with the corresponding Fourier transform measured at ${ }^{111} \mathrm{Cd}$ in the $\mathrm{Au}_{3} \mathrm{In}$ compound. 


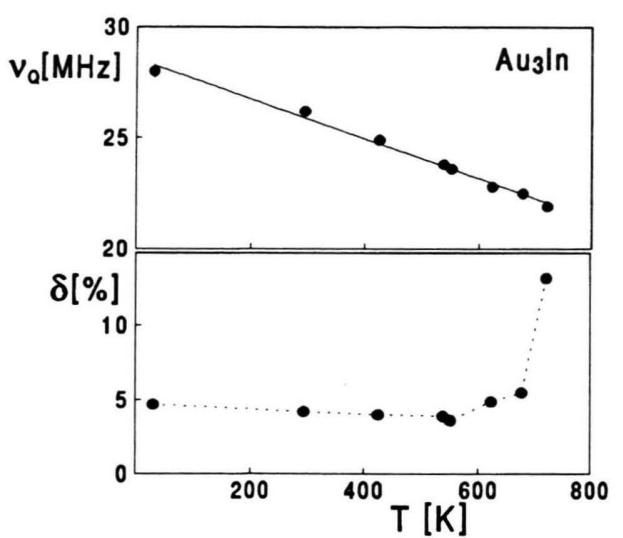

Fig. 6. Temperature dependence of the quadrupole frequency $v_{Q}$ and the width $\delta$ of EFG distribution at ${ }^{111} \mathrm{Cd}$ in the $\mathrm{Au}_{3} \mathrm{In}$ compound.

\subsection{The $\psi$ Phase $\left(A u_{62} \operatorname{In}_{38}\right)$}

This compound was identified by Schubert et al. [14] as isotypic with $\mathrm{Ni}_{2} \mathrm{Al}_{3}$. According to the phase diagram (Figure 2) this phase is formed between 500 and $540 \mathrm{~K}$ and extends from 35.5 to 39.5 at.\% In at $730 \mathrm{~K}$ [7], narrowing to $\approx 39$ at. $\%$ at $497 \mathrm{~K}$.

Four samples of 36.7, 38.6, 39.5 and 39.7 at.\% indium concentrations were prepared, and for all of them measurements over a wide temperature range were performed. A typical PAC spectrum measured at room temperature, i.e. below the temperature range of the discussed phase, is presented in Figure 7. One quadrupole frequency of $156(1) \mathrm{MHz}$ with the corresponding asymmetry parameter $\eta=0.57(1)$ was observed in this experiment with a width $\delta$ of the frequency distribution of about $10 \%$. This frequency exhibits a linear decrease with temperature described by the parameters $v_{Q}(0)=163(2) \mathrm{MHz}$ and $a=1.7(3) 10^{-4} \mathrm{~K}^{-1}$ (see (3)). The value of the $\delta$ parameter increased drastically above $\approx 550 \mathrm{~K}$, and the PAC spectra taken in the temperature region reported for the $\mathrm{Au}_{3} \mathrm{In}_{2}$ phase are strongly damped (see Figures 7 and 8). All the PAC spectra taken between the $\mathrm{Au}_{3} \mathrm{In}_{2}$ phase boundaries $(500 \mathrm{~K}-730 \mathrm{~K})$ resulted in similar spectra with a very large frequency distribution. This findings do not confirm the existence of an ordered phase in that region of the phase diagram. The 3-days annealing of the samples at the appropriate temperatures as well as the quenching did not improve the PAC spectra. The lack of a clear PAC signal, i.e. of a well defined axially symmetric EFG attributed to the one indium site, reported for this structure by Schubert et al. [5], is surprising and can only be explained by a disordered character of the discussed phase. It should, however, be pointed out that our result corroborates the phase diagram reported by Hansen et al. [15], where the $\mathrm{Au}_{3} \mathrm{In}_{2}$ phase is not evidenced.

\subsection{The Solid Solution}

This phase of h.c.p. A3-type structure $[7,11]$ has the indium solubility range between 13 and 23 at.\% and decomposes peritectically. The PAC measurement for the $\mathrm{Au}_{84} \mathrm{In}_{16}$ sample resulted in a broad frequency distribution around $v_{Q}=10.6(8) \mathrm{MHz}$. The large $\delta$ value of ca. $22 \%$ reflects the disordered structure of a solid solution.
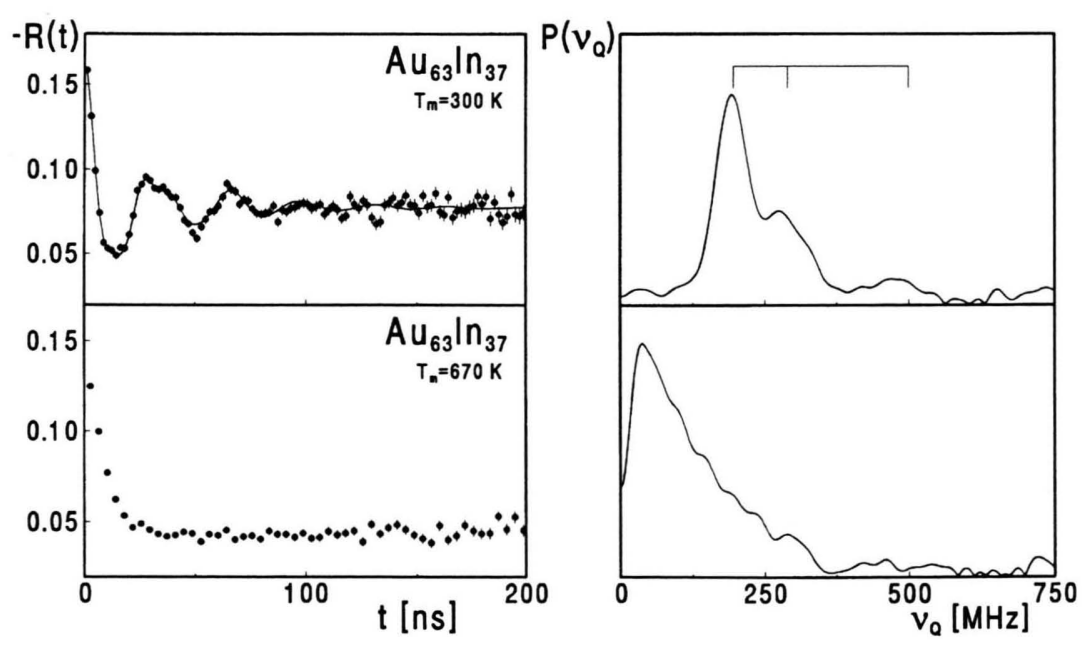

Fig. 7. PAC spectra with the corresponding Fourier transforms measured at ${ }^{111} \mathrm{Cd}$ in an $\mathrm{Au}_{63} \operatorname{In}_{37}$ sample at different temperatures $T_{m}$. 


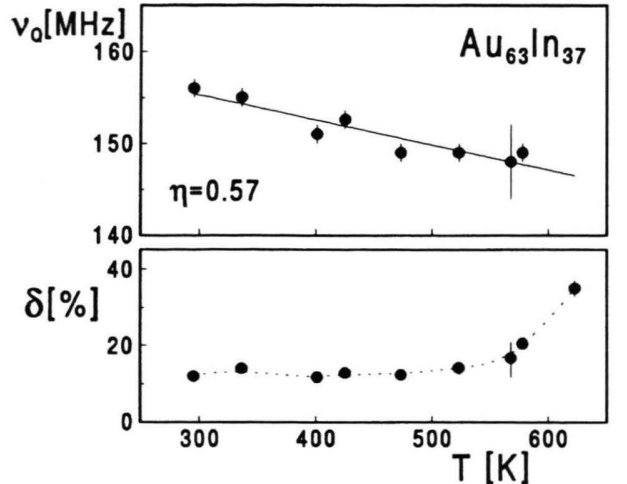

Fig. 8. Temperature dependence of the quadrupole frequency $v_{Q}$ and the width $\delta$ of EFG distribution at ${ }^{111} \mathrm{Cd}$ in an $\mathrm{Au}_{63} \mathrm{In}_{37}$ sample.

\subsection{The $\alpha_{1}$ Phase ( $A u_{7}$ In)}

The $\alpha_{1}$ phase is stable around 11.5 at. $\%$ In and decomposes by a peritectic reaction. Its hexagonal crystallographic structure is reported as $\mathrm{DO}_{24}\left(\mathrm{Ni}_{3} \mathrm{Ti}\right)$ type [11] or the Nd-type [7]. The PAC pattern measured for the $\mathrm{Au}_{88.1} \mathrm{In}_{11.9}$ sample annealed for one day at $780 \mathrm{~K}$ was described by a large frequency distribution around $11.3(6) \mathrm{MHz}(\delta=33(3) \%)$. Therefore, it appears better to regard the structure as being of the Nd-type and not of the $\mathrm{Ni}_{3}$ Ti-type, since the latter is a definitely ordered structure for which two unique axially symmetric EFGs should be expected.

[1] V. Simić and Z. Marinković, Thin Solid Films 41, 57 (1977).

[2] W. Keppner, R. Wesche, T. Klas, J. Voigt, and G. Schatz, Thin Solid Films 143, 201 (1986).

[3] H. Frauenfelder and R. M. Steffen, in K. Karlsson, E. Matthias, and K. Siegbahn (eds.), Alpha-, Beta- and Gamma-Ray Spectroscopy, Vol. 2, North-Holland, Amsterdamn 1963, P. 1118.

[4] P. Herzog, K. Freitag, M. Reuschenbach, and H. Walitzki, Z. Phys. A 294, 13 (1980).

[5] K. Schubert, U. Rösler, and L. Härle, Naturwissenschaften 40, 437 (1953).

[6] H. Haas and D. A. Shirley, J. Chem. Phys. 58, 3339 (1973).

[7] S. E. R. Hiscocks and W. Hume-Rothery, proc. R. Soc. London, Ser. A 282, 318 (1964).

[8] M. Pusejl and K. Schubert, J. Less-Common Met. 41, 33 (1975).

\section{Conclusions}

The quadrupole interaction parameters for the ${ }^{111} \mathrm{Cd}$ probe in different phases of the $\mathrm{Au}$-In system were determined. The results of PAC measurements for $\mathrm{Au}_{3} \mathrm{In}, \mathrm{Au}_{9} \mathrm{In}_{4}, \mathrm{Au}_{7} \mathrm{In}_{3}, \alpha_{1}$ and $\zeta$ phases are in agreement with the corresponding structures given in the literature.

For the $\mathrm{Au}_{70} \mathrm{In}_{30}$ sample a new metastable structure modification was found. In the AuIn compound a polymorphic transition was observed at ca. $630 \mathrm{~K}$.

The results for the $\mathrm{Au}_{62} \mathrm{In}_{38}$ stoichiometry do not confirm the existence of the ordered phase isotypic with $\mathrm{Al}_{3} \mathrm{Ni}_{2}$. Also an attempt to observe the $\beta_{1}$ phase (of 22 at. $\%$ average indium concentration) with $\mathrm{Cu}_{10} \mathrm{Sb}_{3}$ type structure [16], where one unique nonaxially symmetric EFG is expected, failed.

Detailed XRD investigations of the Au-In alloys around 30 and 50 at.\% indium concentration are needed to clarify the structure of the new phases observed with the PAC method. Further experiments concerning the formation of the intermetallic Au-In compounds at the interfaces of bi- and multilayer Au-In samples are in progress.

Work supported in part by the State Committee for Scientific Research

(Grant No. 2 P 302132 07).

[9] P. Wodniecki, B. Wodniecka, M. Marszałek, and A. Z. Hrynkiewicz, Acta Physica Polonica A 88, 333 (1995).

[10] J. P. Goral and L. Eyring, J. Less-Common Met. 116, 63 (1975).

[11] J. Wegst and K. Schubert, Z. Metallkd. 49, 533 (1958).

[12] Pearson's Handbook of Crystallographic Data, P. Villars and L. D. Calved (eds.), 1991.

[13] H. Okamoto and T. B. Massalski, Binary Alloy Phase Diagrams 1987.

[14] J. Schubert, H. Breimer and R. Gohle, Z. Metallkd. 50, 146 (1959).

[15] M. Hansen, Constitution of Binary Alloys, McGrawHill, 1958.

[16] K. Schubert, M. Balk, S. Bhan, H. Breimer, P. Esslinger and E. Stolz, Naturwissenschaften 46, 647 (1959). 